\title{
Effect of Accumulated Strain on the Microstructure and Properties of TC4 Alloy Prepared by Continuous Various Cross-section Recycled Extrusion
}

\author{
X.L. You, Y.Y. Liu, J.S. Hua, K. Wang \\ Xi' an University of Architecture \& Technology \\ Xi'an 710055, China
}

\author{
W. Yao \\ China Petroleum Pipeline Engineering Corporation Civil \\ Department \\ Langfang 065000, China
}

\begin{abstract}
The TC4 titanium alloy were deformed at $800^{\circ} \mathrm{C}$, $2 \mathrm{~mm} / \mathrm{s}$ with various extrusion loops by a new sever plastic deformation method-Continuous Various Cross-section Recycled Extrusion, then the microstructure and microhardness of the specimen along the radial, the maximum deformation force in each extrusion procedure were also investigated. The results show that Continuous Variable Cross-section Recycled Extrusion is a better method for obtaining TC4 alloy with fine and equiaxed microstructure. With the increase of extrusion loops from 3 to 6 , the grain size decreases and its size are about 2 to $3 \mathrm{um}$. As the extrusion loops increases from 6 to 8, the grain size is similar to that of the 6 loops. However, the grain size increases slightly due to multiple heating as the extrusion loops increases from 8 to 12. Moreover, the microhardness and maximum deformation force of the specimen in each extrusion procedure are higher while the extrusion loops is from 6 to 8 . Therefore, the extrusion loop of 6 is the optimal, the microstructure is fine and equiaxed and it also distributes homogeneously.
\end{abstract}

Keywords-continuous various cross-section recycled extrusion; TC4 titanium alloy; accumulated strain; microstructure; properties

\section{INTRODUCTION}

Titanium alloys are widely used in the aerospace industry due to their low density, high strength and toughness as well as good high-temperature properties. Mechanical properties of titanium alloys are important criteria of material service capabilities both in aerospace and industrial applications. It is well known that the microstructure of the alloy is one of the important factors controlling its properties. If the titanium alloy with equiaxed, fine and homogeneous microstructure is obtained by some methods, its plasticity and strength will also improved significantly [1].

In recent years, in order to obtain the titanium alloys with equiaxed, fine and homogeneous microstructure, many methods are used, such as Equal Channel Angular Press(ECAP)[2-4], Multiple Forging(MF)[5], High Pressure Torsion(HPT)[6-7], Cyclic Extrusion Compression(CEC), Accumulative Roll Banding(ARB), High Ratio Extrusion(HRE), and Continuous Variable Cross-section Recycled Extrusion(CVCE)[8-10], etc.

Continuous Variable Cross-section Recycled Extrusion (CVCE) is a new method of sever plastic deformation(SPD), its advantages are as flows: (1) the large size block materials with fine grain microstructure can be obtained; (2) the cost of die is low and the operation is simple; (3) the drum occurring in the traditional upsetting is eliminated, and the geometrical shape can be kept simultaneously; (4) the efficiency is high, and the quality is also good.

Therefore, in order to obtain the titanium alloy with fine and equiaxed microstructure, the TC4 titanium alloy is deformed with various extrusion loops by CVCE, and the effect of extrusion time on the microstructure, hardness and maximum deformation force have been investigated. The results will provide a new method with better process parameters and theoretical guidance for preparing the large size bulk titanium alloy with fine and equiaxed grain.

\section{EXPERIMENTAL}

The TC4 alloy used in the present work was a bar of $\Phi 20 \mathrm{~mm}$ in diameter. The beta transus temperature of the TC4 alloy is $989^{\circ} \mathrm{C}$, and its chemical composition is shown in Table 1. The initial microstructure of the TC4 alloy is a typical equiaxed structure consisting of a large volume fraction of fine equiaxed $\alpha$ phase with a grain size of 12 um and a small amount of transformed $\beta$ phase, as shown in Figure 1.

TABLE I. CHEMICAL COMPOSITION OF TC4 ALLOY (MASS FRACTION, \%).

\begin{tabular}{|l|l|l|l|l|l|l|l|}
\hline $\mathrm{Al}$ & $\mathrm{V}$ & $\mathrm{O}$ & $\mathrm{N}$ & $\mathrm{C}$ & $\mathrm{Fe}$ & $\mathrm{H}$ & $\mathrm{Ti}$ \\
\hline 6.5 & 4.3 & 0.2 & 0.05 & 0.10 & 0.30 & 0.02 & Bal. \\
\hline
\end{tabular}

The cylinder specimens were electro-discharged machined from the bar with a length of $26 \mathrm{~mm}$. In order to avoid the cracks formation during extrusion because of the stress concentration occurring in the sharp edge, the cut surfaces were filleted and shined with abrasive papers. 


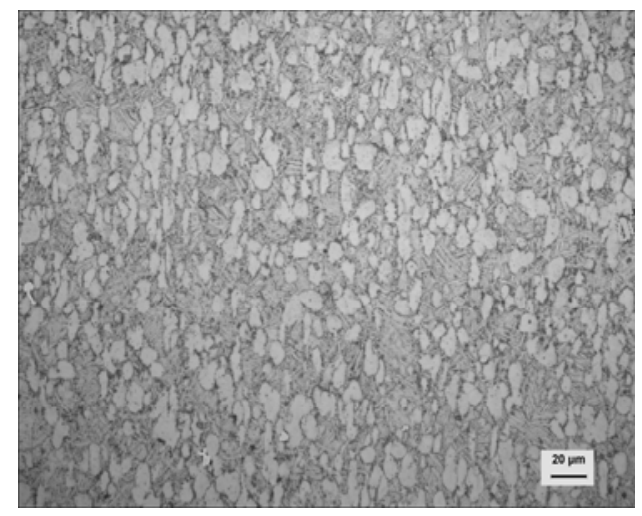

FIGURE I. INITIAL MICROSTRUCTURE OF TC4 TITANIUM ALLOY.

The flow diagram of CVCE is shown in Figure 2. It can be seen that a deformation loop is composed of four procedures, including two times extrusion from the cylinder to the frustum of cone in die cavity; two times upsetting from the frustum of cone to the cylinder. The deformation account is obtained by accumulated extrusion and upsetting. Finally, the TC4 alloy with fine and equiaxed microstructure will be obtained by accumulated strain.

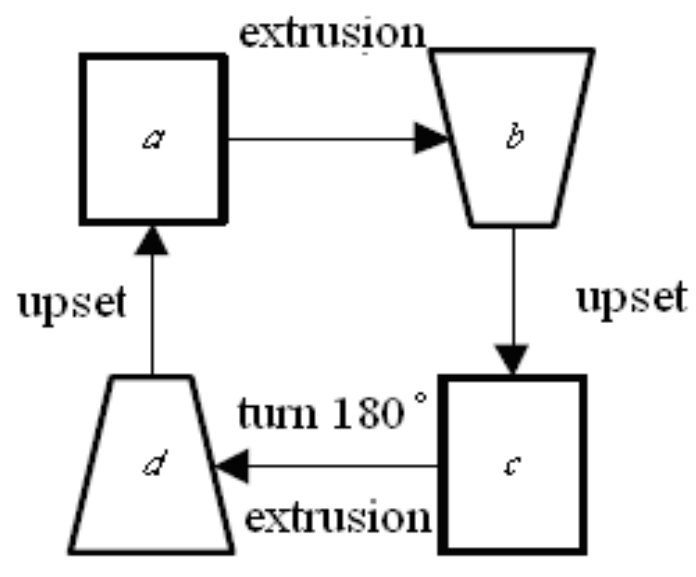

FIGURE II. EXTRUSION PROCESS FLOW OF CVCE.

The tests were carried out using a hydraulic press with controllable speed. The deformation temperature used was 800 ${ }^{\circ} \mathrm{C}[10]$, and the speed was $2 \mathrm{~mm} / \mathrm{s}$. The extrusion loops were 3 , 6,8 and 12 , respectively. The heating time was calculated by $0.6 \mathrm{~mm} / \mathrm{minute}$, and the specimen was heated by 10 minutes between two procedures for improving the plastic deformation ability of TC4 titanium alloy. In deformation, H13 tool steel was used as the die materials, and its temperature was kept at $550^{\circ} \mathrm{C}$. After the total deformation, the specimen was cooled in water. Moreover, in heating and deformation, the surfaces of specimens were coated with special glass lubrication to resist oxidation. However, the surface of die cavity was coated with the mixing uniform graphite powder and oil.

The microstructure of TC4 alloy along the radial direction was observed by an optical microscopy (OLYMPUS PM-G3), and the microhardness was measured by 401MD microindenter with a load of $100 \mathrm{gf}$ applied for a dwell time of
$15 \mathrm{~s}$. The specimen were etched with a solution containing 40 vol. $\% \mathrm{HF}+30$ vol. $\% \mathrm{HNO}_{3}$ in water.

\section{RESULTS AND DISCUSSION}

The microstructure of the TC4 alloy deformed at $800^{\circ} \mathrm{C}$ with $2 \mathrm{~mm} / \mathrm{s}$ by various extrusion loops (various accumulated strain) is show in Fig.3. It can be seen that the grain size decreases as the extrusion loop increases from 3 in Fig.3a to 6 in Fig. $3 \mathrm{~b}$, and the grain size of 6 loops is about 2 to $3 \mathrm{um}$. As the extrusion loop increases from 6 to 8 , the grain size is fine, this is similar to that of 6 loops in Figure 3c. However, the grain size increases slightly as the extrusion loops increases from 8 to 12 , and its grain size is about 3 to 4 um. The reason is that with the increase of extrusion loop from 3 to 6 or 8 , the accumulated strain increases, so the microstructure is broken sufficiently and show the fine and equiaxed shape. Moreover, although the accumulated strain increases with the increase of extrusion loop from 8 to 12 , the microstructure is coarsen slightly due to multiple heating with the increase of extrusion loop.

From above mentioned, the better extrusion loop is from 6 to 8 , the microstructure of grain size with about 2 to 3 um can be obtained by CVCE. But considering the uniformity of microstructure distribution and deformation efficiency, the extrusion loop of 6 is the optimal.
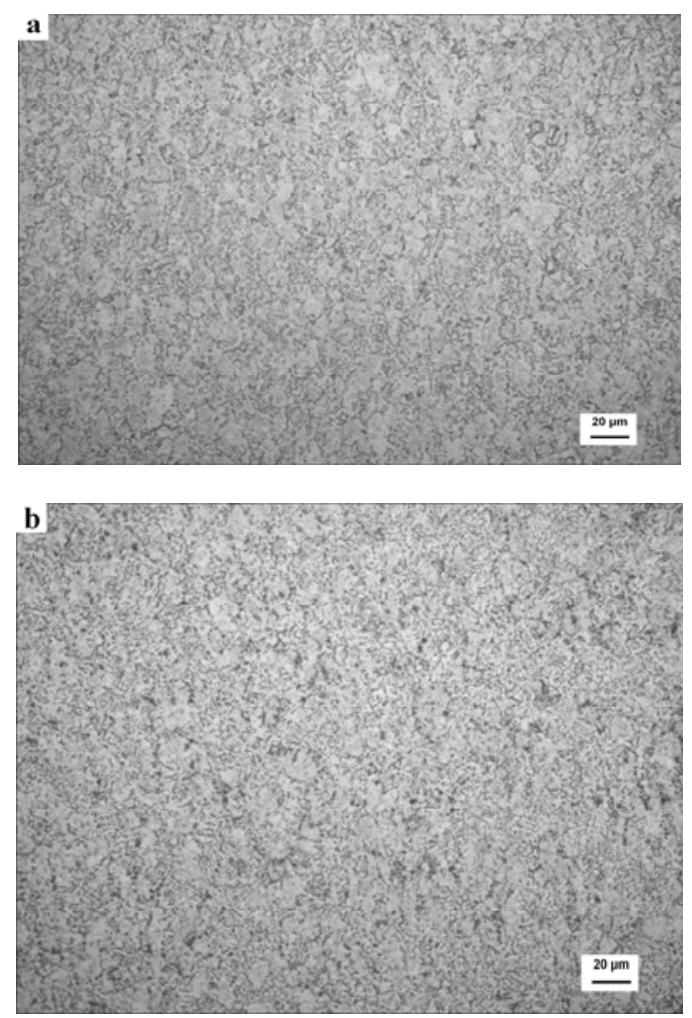

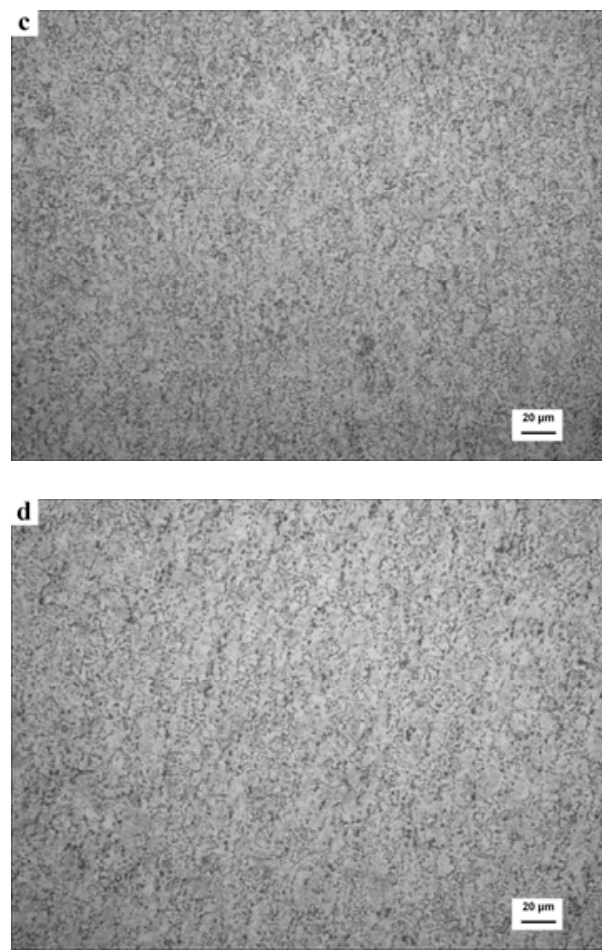

FIGURE III. MICROSTRUCTURE OF THE TC4 ALLOY UNDERGONE VARIOUS DEFORMATION LOOPS(VARIOUS ACCUMULATED STRAIN): (a) 3; (b) 6; (c) 8; (d) 12 .

The microhardness of the TC4 alloy deformed at $800^{\circ} \mathrm{C}$ with $2 \mathrm{mms}$ by various extrusion loops (various accumulated strain) is show in Figure4. It can be seen that the change law between microhardness and extrusion loop is in accordance with that of microstructure and extrusion loop. For example, while the extrusion loop is $3,6,8$ and 12 , the microhardness value is $278.7 \mathrm{MPa}, 298.7 \mathrm{MPa}, 298.1 \mathrm{MPa}$, and $287.9 \mathrm{MPa}$, respectively. Based on the above microhardness value, the extrusion loop of 6 is also the optimal.

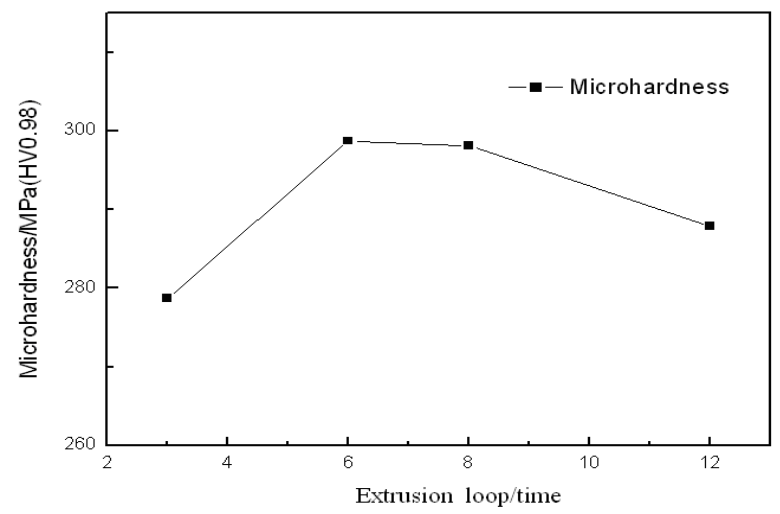

FIGURE IV. MICROHARDNESS OF TC4 ALLOY UNDERGONE VARIOUS DEFORMATION LOOPS AT $800^{\circ} \mathrm{C}$ WITH $2 \mathrm{MM} / \mathrm{S}$ (VARIOUS ACCUMULATED STRAIN)

The relationship between maximum deformation force and extrusion loop from 4 to 10 in each extrusion procedure is shown in Table 2. It can be seen that as the extrusion loop is from 6 to 8 , whatever in the extrusion procedure or the upset one, the deformation force of the TC4 alloy is higher comparing to the other extrusion loop. The reason is that the grain size decreases and the homogeneity of distribution increases with increasing extrusion loop, which results in the increases of maximum deformation force. In addition, it is concluded that the deformation force in the extrusion procedure of each loop is smaller than that in the upsetting procedure. With the increase of extrusion loop from 9 to 10 , the deformation force decreases obviously. For example, in the second procedure and fourth procedure of 8 and 10, the deformation force decreases from $400 \mathrm{KN}$ to $309 \mathrm{KN}$ and from $384 \mathrm{KN}$ to $292 \mathrm{KN}$, respectively, this is related to the microstructure coarsening with the increase of deformation loop.

TABLE II. RELATIONSHIP BETWEEN MAXIMUM DEFORMATION FORCE AND EXTRUSION LOOP IN EACH EXTRUSION PROCEDURE (ACCUMULATED STRAIN)

\begin{tabular}{|l|l|l|l|l|}
\hline \multirow{2}{*}{$\begin{array}{l}\text { Extrusion loop } \\
\text { (loop) }\end{array}$} & \multicolumn{4}{|c|}{ Deformation force per procedure $(\mathrm{KN})$} \\
\cline { 2 - 5 } & $1^{\text {st }}$ & $2^{\text {st }}$ & $3^{\text {st }}$ & $4^{\text {st }}$ \\
\hline 4 & 358 & 376 & 348 & 397 \\
\hline 5 & 340 & 390 & 348 & 383 \\
\hline 6 & 343 & 392 & 341 & 388 \\
\hline 7 & 326 & 433 & 319 & 400 \\
\hline 8 & 308 & 400 & 339 & 384 \\
\hline 9 & 322 & 377 & 266 & 300 \\
\hline 10 & 300 & 309 & 274 & 292 \\
\hline
\end{tabular}

\section{CONCLUSIONS}

1) The grain size decreases as the extrusion loop increases from 3 to 6 , which is related to the increase of accumulated strain. When the extrusion loop increases to 8 , the grain size is similar to that of the 6 loop. However, the grain size increases slightly due to multiple heating as the extrusion loop increases from 8 to 12 .

2) The micro hardness and maximum deformation force of the specimen in each extrusion procedure are higher as the extrusion loop increases from 6 to 8 , which are related to the fine microstructure and its homogeneous distribution.

3) Considering the uniformity of microstructure distribution and deformation efficiency, the extrusion loop of 6 is the optimal, and the microstructure of grain size with about 2 to 3 um can be obtained by CVCE.

\section{ACKNOWLEDGMENT}

This work was financially supported by the Natural National Science Foundation of China (51101116).

\section{REFERENCES}

[1] S. M. Sastry, R N. Mahapatra, D. F. Hasson, Microstructural refinement of Ti-44Al-11Nb by severe plastic deformation, Scripta Materialia, 42(2000): 731-736.

[2] Alexander Korshunov, Tamara Kravchenko, Lev Polyakov, Andrey Smolyakov, Irina Vedernikova, Alexander Morozov, Effects of the number of equal-channel angular pressing passes on the anisotropy of ultra-fine titanium, Mater. Sci. and Eng. A , 493(2008): 160-163. 
[3] X.C. Zhao, W.J. Fu, X.R. Yang, Terence G. Langdon, Microstructure and properties of pure titanium processed by equal-channel angular pressing at room temperature, Scripta Materialia, 59(2008): 542-545.

[4] X.C. Zhao, X.R. Yang, X.Y. Liu, X.Y. Wang, Terence G. Langdon, The processing of pure titanium through multiple passes of ECAP at room temperature, Mater. Sci. Eng. A, 527(2010): 6335-6339.

[5] G. A. Salishchev, R. M. Galeyev, S. P. Malysheva, M.M. Myshlyaev, Structure and density of submicrocrystalline titanium produced by severe plastic deformation, Nanostructured Mater., 11(1999): 407-414.

[6] S. Faghihi, A.P. Zhilyaev, J.A. Szpunar, F. Azari, H. Vali, M.Tabrizian. Nanostructuring of titanium material by high pressure torsion improves pre-osteoblast attachment, Adv.Mater., 19(2007): 1069-1073.

[7] F. Shahab, A. Fereshteh, Z.P. Alexander, A.S. Jerzy, V. Hojatollah, T. Maryam. Cellular and molecular interactions between MC3T3-E1 pre-osteoblasts and nanostructured titanium produced by high-pressure torsion Biomaterials, 28(2007): 3887-3895.

[8] C.R.Liu, H.X..Ren, Q.J.Wang, Microstructure and properties of AZ31 Magnesium alloy by Continuous Variable Cross-section Recycled Extrusion, Light Alloy Fabrication Technol., 37(6) (2009): 34-37 ( In Chinese).

[9] J.Zhang, C.R.Liu, Q.J. Wang, K.S. Wang, Z.Q.Ma,Structural Evolution of Pure Aluminum1A85 During Continuous Variable Cross-section Recycled Extrusion, J. Mater. Sci. Eng., 28(6) (2010):930-933 ( In Chinese).

[10] Y. Y. Liu, C.R. Liu, L. Wang, Y.Z. Zhang, Effects of processing parameters of Continuous Variable Cross-Section Recycled Extrusion on the microstructure and micro hardness of TC4 titanium alloy, Rare Met Mater. Eng., 43(2) (2014):440-444 (In Chinese). 